\title{
Schwa Deletion in Hindi Language Speech Synthesis
}

\author{
Damodar Magdum, Tejaswini Patil, Maloji Suman
}

\begin{abstract}
Schwa deletion is important factor for conversion of Grapheme to Phoneme. In Hindi language each consonant has weak vowel. This weak vowel is called as inherent schwa. These schwa is deleted some cases in pronunciation. Written form and speech forms are different in Indian language. Schwa plays important role in speech form. Deletion and retention of weak vowel decides how words are pronounced. Words morphology is main factors that affects pronunciation. In current paper, we describe schwa handling, deletion and retention rules. Based on different rule we developed schwa deletion algorithm. This algorithm has been tested over 6000 high frequency words. We received accuracy result up to $80 \%$. Based on result an application has been developed to provide user interface for the text processing component of text to speech system.
\end{abstract}

Keywords - Schwa, grapheme to phoneme, weak vowel, inherent schwa, pronunciation

\section{INTRODUCTION}

Hindi is the major language in India spoken by $41 \%$ population of India and other language speakers (for each language) are less than 9\% as per census India data [12]. However, good quality Hindi Text To Speech (TTS) is not available to deploy in real time applications. Though, many Indian language prototypes are available, the quality is not up to commercial use. The quality of Text To Speech (TTS) greatly depends upon linguistic knowledge such as grapheme to phoneme mapping, schwa deletion, syllable structure and pronunciation dictionary.

Pronunciation lexicons are the interface between grapheme (written form) and phoneme (interpretation / spoken form). For a natural language it is not possible to explicitly list all the words in that language. So, when a new word comes up which is not explicitly listed, the lexical lookup fails in that case as discussed by Ohala [3]. This necessitates conversion from grapheme to phoneme to generate pronunciation lexicon in text to speech systems. Hence, rule based grapheme-tophoneme processes any input orthographic unit sequence to build pronounceable phoneme sequence as discussed in signal processing and acoustic portal [11]. But, orthographic form deviates from the pronounceable form. The way a word is written is not as it is pronounced. Complexities like nasals, ligatures have to be formulated.

In Hindi languages, schwa deletion plays a crucial role in appropriate pronunciation. Orthographic form does not provide any indicators that where schwa needs to be dropped. Schwa deletion is extremely important for

Revised Manuscript Received on August 14, 2019.

Damodar Magdum, Research Scholar, Koneru Lakshmaiah Education Foundation, Vaddeswaram (A.P., INDIA). (E-mail: damodarm@cdac.in)

Tejaswini Patil, Principal Technical Officer, C-DAC, GIST, Pune

Dr. Maloji Suman, Professor, Koneru Lakshmaiah Education Foundation, Vaddeswaram (A.P., INDIA). (E-mail: suman.maloji@cdac.in) (M.S., INDIA). (E-mail: tejaswinip@cdac.in)

intelligibility speech. Schwa is a mid-central unstressed vowel that occurred normally in unstressed syllables.

Each consonant in Hindi has inherent schwa (weak vowel) which is not shown orthographically.

$$
\text { Example : कलम }=/ \mathrm{k} 111 \mathrm{~m} /
$$

These are deleted in some cases in pronunciation. To handle schwa deletion and insertion, already work has been done to define schwa deletion rules and algorithm. For Hindi, two main issues are handled in Narasimhan, Sproat, Kiaraz work [1]. First, not every schwa following a consonant is pronounced within the word. Second, in multi morphemic words, the presence of a morpheme boundary can block schwa deletion where it might otherwise occur. Linguistic literature by Ohala [3] has discussed schwa deletion rules and its behavior in morphological boundaries. Pray [4] made a proposal that schwa deletion rule applies from right to left.

\section{Example $:$ निकलवा $=/$ nik1lwa/ .}

But, application of these rules on words like करवट $=/$ k1r1w1t'/ produces wrong output करव्ट $=/ \mathrm{k} 1 \mathrm{r} 1 \mathrm{wt} ' /$. The correct pronunciation is कर्वट $=/ \mathrm{k} 1 \mathrm{rw} 1 \mathrm{t} \%$. Analysis of data concludes that traversal from left-to-right, produces less such exceptions. Further, morphological separation of root words increases accuracy of identification and deletion of schwa. Practically, present schwa deletion algorithm [5] need many traversals through input string.

Our proposed schwa deletion method based on different schwa deletion rules. Pronunciation lexicon is the interface between visual form of text and auditory form i.e. speech. In TTS, target waveform selection is determined by phonemic representation of input text. Standard Hindi dictionaries contain meaning and phonemic pronunciation of word. But, none of dictionaries consider issue of pronunciation lexicon which as per World Wide Web Consortium (W3C) [13] is taking account of. Some institutes working on linguistics have prepared pronunciation lexicons. A pronunciation lexicon specifies pronunciation variants of word. Applications of TTS, automatic speech recognition (ASR) uses dynamic vocabulary. But, it is impractical to establish pronunciation lexicon with full coverage and therefore automatic grapheme to phoneme module is called for words which are not present in lexicon. Even pronunciation lexicon in TTS like systems take large space and searching slows down the performance of system. 
Figure 1 shows Text processing flow of text to speech system. Invalid word कित्ताब is corrected using text cleaning module before passing it to grapheme to phoneme module. It is useful to avoids wrong phonetic mapping of word कित्ताब. After generation of grapheme to phoneme, word is passed to schwa deletion module for further processing.

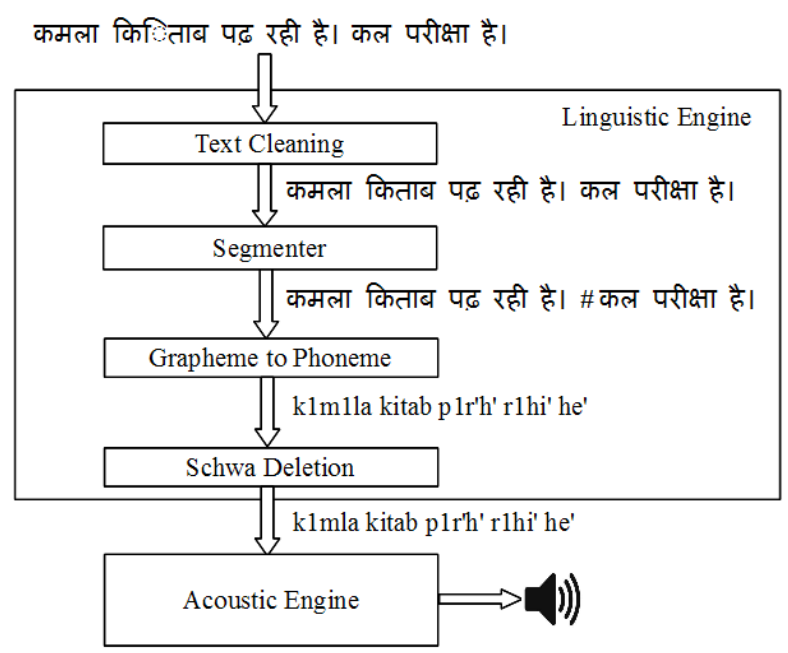

Fig. 1. Text Processing Flow.

Grapheme to phoneme is a process of mapping word represented by sequence of graphemes to its pronunciation form, represented by a sequence of phonemes. Data driven algorithms are used to infer rules for grapheme-to-phoneme (G2P) automatically [11]. The data driven approach works similar as rule based approach, with question set stored in decision tree. It needs huge manual training for selflearning. In this approach, input word is scanned for matching in trained dataset and alignment is done for corresponding pronunciation. But, there are issues in alignment as there is not one-to-one mapping every time. Grapheme and phoneme lengths are always of not same length, hence null grapheme or null phoneme must be inserted for proper alignment [10].

Example: a. Single grapheme -> two phonemes

$$
\text { क्ष }=/ \mathrm{ksh} \text { \% }
$$

b. Two graphemes -> single phoneme

$$
\text { क़ }=/ \mathrm{q} /
$$

The most common notation is International Phonetic Alphabet [14]. But, symbols of International Phonetic Alphabet are more used in paper than to computers [8]. Instead of special characters used in International Phonetic Alphabet, we defined our own set of characters phonetic representation using ASCII- table [15]. Traditional rule based approach does not consider context based examples. Mapping of grapheme to phoneme is dependent upon context. So, more than one rule are needed for mapping.

Examples: Anuswara is mapped depending upon next context.

$$
\begin{aligned}
& \text { अंबा }=\text { Anuswara is mapped as } \mathrm{m}=/ 1 \mathrm{mba} / \\
& \text { अंडा }=\text { Anuswara is mapped as } \mathrm{n}=/ 1 \mathrm{nd} \text { 'a/ }
\end{aligned}
$$

\section{GRAPHEME-TO-PHONEME}

Anuswara is mapped to corresponding varga nasal of next consonant.

\section{SCHWA (WEAK VOWEL) DELETION AND RETENTION}

The different rules of schwa mapping, deletion and retention are explained below;

\section{A. Schwa to vowel mapping for ह $/ h /$}

Orthographic form of words containing ह is pronounced differently. Schwa succeeding ह is mapped to matra $\breve{b}$ while pronunciation. Observing pronunciation of such a data by native speakers, rules are formed and validated. If word has schwa $+\mathrm{h}+$ schwa in phonetic, then schwa is mapped to e' matra as $\mathrm{e}^{\prime}+\mathrm{h}+\mathrm{e}^{\prime}$ [9].

$$
\begin{aligned}
& \text { Examples: a. कहकर =/ke'he'k1r/ } \\
& \text { b .बहन =/be'he'n/ } \\
& \text { c. बहना =/be'he'na/ } \\
& \text { d. सहकारी =/se'he'kari'/ }
\end{aligned}
$$

\section{B. Schwa (weak vowel) retention}

- Schwa in first syllable is always retained.

$$
\begin{array}{r}
\text { Examples: a. अलग }=/ 111 \mathrm{~g} / \\
\text { b. समर }=/ \mathrm{s} 1 \mathrm{~m} 1 \mathrm{r} /
\end{array}
$$

- Schwa following conjugate syllable with final consonant as $\mathrm{y} / \mathrm{r} / \mathrm{l} / \mathrm{w}$ is retained.

$$
\begin{aligned}
& \text { Examples: a. श्राव्य=/sh'rawy1/ } \\
& \text { b. साफल्य =/saph'1ly1/ }
\end{aligned}
$$

- Schwa following conjugate syllable is always retained.

$$
\begin{aligned}
& \text { Examples: a. आमंत्रण =/am1ntr1n'/ } \\
& \text { b. संप्रदाय=/s1 mpr1day/ }
\end{aligned}
$$

- Schwa after final character $\mathrm{h}$ is always retained.

$$
\begin{aligned}
& \text { Examples: a. लोह=/loh1/ } \\
& \text { b. विरह=/wir 1h1/ }
\end{aligned}
$$

- If schwa is preceding full vowel then schwa is retained.

$$
\begin{aligned}
& \text { Examples: } \text { a. अलग }=/ 111 \mathrm{~g} / \\
& \text { b. समई }=/ \mathrm{s} 1 \mathrm{~m} 1 \mathrm{i}^{\prime} /
\end{aligned}
$$

- If $य / y /$ is final character preceded by vowels like a, $i, i$, $u, u^{\prime}$ then, schwa is retained. Whereas if preceded vowel is 1 , e, e' then schwa is deleted.

$$
\begin{aligned}
& \text { Examples: a. प्रिय }=/ \text { priy } 1 / \\
& \text { b. काव्य }=/ \text { kawy } 1 / \\
& \text { c. लय }=/ 11 \mathrm{y} /
\end{aligned}
$$

- Schwa (weak vowel) deletion

If schwa deletion is not combining more than two 
consonants then the schwa is deleted.

$$
\begin{gathered}
\text { Examples: a. लोकतंत्र }=/ \text { lokt } 1 \mathrm{ntr} 1 /, \\
\text { b. पन्द्रह }=/ \mathrm{p} 1 \mathrm{ndr} 1 \mathrm{~h} 1 /
\end{gathered}
$$

- Schwa is deleted only when there is preceding and succeeding vowel.

$$
\text { Examples: a. सतरंज }=/ \mathrm{s} 1 \mathrm{tr} 1 \mathrm{nj} /
$$

\section{ALGORITHM FOR SCHWA DELETION}

Input word: String of phonemes.

Output: Input word with some of the schwas deleted [6, 7].

1. Mark all the full vowels in string of phonemes.

2. If vowel Count $<3$ then do not delete schwa (1). As schwa in first syllable is always retained and second schwa is inserted only in specific conditions as motioned in schwa deletion rules

3. Else for vowel Count $>=3$ check vowel at vowel Position $=2$,

3.1. If vowel $==$ Schwa (1) then check for consonant count between vowel Position $=1$ and vowel Position $=3$

3.2. If consonant Count $>2$ then do not delete schwa (1).

3.3. Else count consonants between vowelPos 2 and vowelPos3.

3.4. If consonant Count $=0$ then do not delete schwa (1). As succeeding matra will combine with consonant and it will change word itself.

3.5. Else delete schwa (1).

Nasal is considered as consonant.

\section{APPLICATION}

An Application has been developed to provide user interface for the text processing component. It takes word as input for text processing and generates pronounceable form of word i.e. phoneme string. Input can be taken in two forms: By browsing text file containing line separated words and by inputting word in text box. Output can be saved in text file (Figure 2).

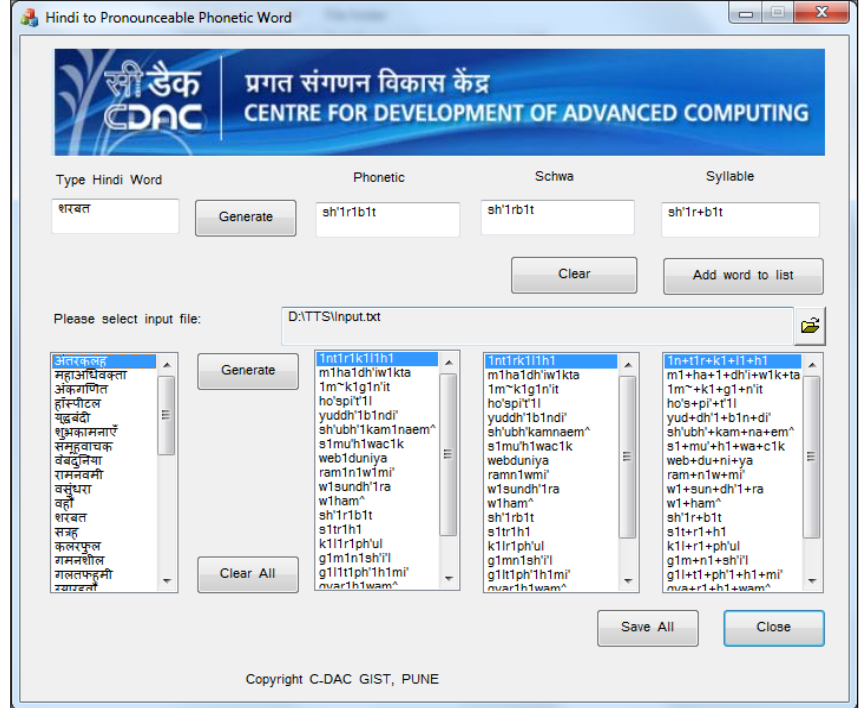

Fig. 2. Hindi to Pronounceable Phonetic word.

\section{RESULTS}

Testing has been done on high frequency 6000 Hindi words. Testers having phonological knowledge of Hindi were used. Testers were of category native speakers, researchers in linguistics, testers for language technology products (see Table1). where Vowel classification is shown in Table 2.

Grapheme to phoneme conversion is direct one to one mapping with Hindi specific rules. So, it gives expected result for all the strings. Schwa deletion is rule based so there are possibilities of wrong schwa deletion and retention $[1,2]$.

Complete Data under test contains:

Input $=6000$ words

Wrong schwa deletions $=120$ words

Correct result set $=4800$ words

If schwa deletion gives wrong output then the split syllable will also be wrong. If word is formed by joining two different root words or attaching prefix or suffix then

\begin{tabular}{|c|c|c|c|c|c|}
\hline $\begin{array}{c}\text { Hindi Unicode } \\
\text { Word }\end{array}$ & Phonetic & Schwa Deleted & Syllable splitter & \begin{tabular}{|c|} 
Mark Wrong \\
Schwa deletion
\end{tabular} & \begin{tabular}{|} 
Mark Wrong \\
Split word
\end{tabular} \\
\hline अंतरकलह & 1nt1r1k111h1 & 1nt1rk111h1 & $1 \mathrm{n}+\mathrm{t} 1 \mathrm{r}+\mathrm{k} 1+\mathrm{l} 1+\mathrm{h} 1$ & Correct & Correct \\
\hline महाअधिवक्ता & m1ha1dh'iw1kta & m1ha1dh'iw1kta & m1+ha+1+dh'i+w1k+ta & Correct & Correct \\
\hline अंकगणित & 1m k1g1n'it & 1m k1 gn'it & $1 \mathrm{~m} \sim+\mathrm{k} 1 \mathrm{~g}+\mathrm{n}$ 'it & Wrong & Wrong \\
\hline हॉस्पीटल & ho'spi't'11 & ho'spi't'11 & ho's+pi'+t'11 & Correct & Correct \\
\hline शुभकामनाएँ & 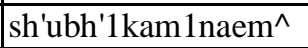 & sh'ubh'kamnaem^^ & sh'ubh'+kam+na+em^^ & Correct & Correct \\
\hline समूहवाचक & s1mu'h1wac1k & s1mu'h1wac1k & $\mathrm{s} 1+\mathrm{mu}+\mathrm{h} 1+\mathrm{wa}+\mathrm{c} 1 \mathrm{k}$ & Correct & Correct \\
\hline रामनवमी & ram1n1w1mi' & ramn1wmi' & ram+n1w+mi' & Correct & Correct \\
\hline वसुंधरा & w1sundh'1ra & w1sundh'1ra & $\mathrm{w} 1+\mathrm{sun}+\mathrm{dh}$ '1+ra & Correct & Correct \\
\hline वहाँ & w1ham^ & w1ham^ & w1+ham^ ${ }^{\wedge}$ & Correct & Correct \\
\hline शरबत & sh'1r1b1t & sh'1rb1t & sh'1r+b1t & Correct & Correct \\
\hline
\end{tabular}
schwa deletion gets wrong and word is split inaccurately.

Table 1. Sample Test Data Set 
SCHWA DELETION IN HINDI LANGUAGE SPEECH SYNTHESIS

\begin{tabular}{|l|l|l|l|l|l|}
\hline सत्रह & s1tr1h1 & s1tr1h1 & s1t+r1+h1 & Correct & Correct \\
\hline कलरफुल & k111r1ph'ul & k1lr1ph'ul & k11+r1+ph'ul & Wrong & Wrong \\
\hline सुप्रिया & supriya & Supriya & sup+ri+ya & Correct & Wrong \\
\hline & & & Result & $80.00 \%$ & $75.00 \%$ \\
\hline
\end{tabular}

Table 2. Vowel classification

\begin{tabular}{|c|c|c|c|}
\hline Articulation & $\begin{array}{c}\text { Monophthongs } \\
\text { (Short) }\end{array}$ & $\begin{array}{c}\text { Monophthongs } \\
\text { (long) }\end{array}$ & Diphthongs \\
\hline Guttural & अ /1/ & आ /a/ & ई /i'/ \\
\hline Palatal & इ /i/ & ऊ/u'/ & ऐ $/ \mathrm{u} /$ \\
\hline Labial & ऋ/ri'/ & ए /e/ & औ /au'/ \\
\hline Retroflex & & ओ /o/ & \\
\hline Palato-Guttural & &
\end{tabular}

\section{CONCLUSION}

Schwa is a mid-central unstressed vowel that occurred normally in unstressed syllables. Accuracy of schwa deletion and retention can be improved by applying morphological knowledge. A set of rules have been developed for Hindi language. Based on different rule schwa deletion algorithm is developed. This algorithm is tested on high frequency Hindi words. The resultant data used will be useful for text to speech system.

\section{ACKNOLEGEMENT}

The author is thankful C-DAC,GIST Pune Team for their help to this work.

\section{REFERENCES}

1. B. Narasimhan, R. Sproat, and G. Kiraz, "Schwa deletion in Hindi Text to Speech Synthesis," International Journal of Speech Technology,2004, 7(4), 319-333.

2. M.L. Dhore, R.M. Dhore, and P.H. Rathod, "Transliteration by orthography or phonology for Hindi and Marathi to English : Case Study," International Journal on Natural Language Computing (IJNLC), 2013,Vol. 2, No.5.

3. O. Manjari, "Aspects of Hindi Phonology," Motilal Banarasidass Delhi,1983.

4. B.R. Pray, "Topics in Hindi Urdu grammar," Centre for South and Southeast Asia Studies, University of California, 1970.

5. C. Monojit, B. Anupam, and S. Sudeshna, "A Diachronic Approach for Schwa Deletion in Indo Aryan Languages," Proceedings of the Workshop of the ACL Special Interest Group on Computational Phonology (SIGPHON), 2004.

6. P. Singh and G.S. Lehal, "A Rule Based Schwa Deletion Algorithm for Punjabi TTS System," International Conference on Information Systems for Indian Languages (ICISIL), pp.98-103,2011.

7. M. Choudhury, "Rule-based grapheme to phoneme mapping for Hindi speech synthesis," Proceedings of $90^{\text {th }}$ Indian Science Congress of the International Speech Communication Association (ISCA), Bangalore, India,2003.

8. Sandeep Kaur and Dr. Amitoj Singh, "Schwa Deletion: Investigating Improved Approach for Text-to-IPA System for Shiri Guru Granth Sahib," International Journal of Advanced Research in Computer and Communication Engineering Vol. 4, Issue 4, April 2015.

9. Sudeshna Sarkar, "Schwa Deletion and Syllable Economy in Indo Aryan Languages," Symposim on Indian
Morphology, Phonology \& Language Engineering, Indian Institute of Technology, Kharagpur, March 2004.

10. Aliya Deri and Kevin Knight, "Grapheme- to-Phoneme Models for (Almost) Any Language, " Proceedings of the 54th Annual Meeting of the Association for Computational Linguistics, Berlin, Germany, pp.399-408,August 2016.

11. A. Iyanda, O.Odéjobí,F.Soyoye, and O.Akinadé, "Development of Grapheme - to - Phoneme Conversion System for Yoruba Text-to-Speech Synthesis, "Journal of Computer Science 13(2): pp.44-53, December 2014.

12. http://www.censusindia.gov.in

13. http://www.w3.org/TR/pronunciation-lexicon/

14. https://en.wikipedia.org/wiki/International_Phonetic_Alph abet

15. BIS IS 13194:1991, Indian Script Code For Information Interchange - ISCII. 